\title{
Gold-catalyzed regioselective oxidation of propargylic carboxylates: a reliable access to $\alpha$-carboxy- $\alpha, \beta$-unsaturated ketones/aldehydes
}

Kegong Ji, Jonathan Nelson and Liming Zhang*

\author{
Full Research Paper \\ Address: \\ Department of Chemistry and Biochemistry, University of California, \\ Santa Barbara, California, 93106, USA \\ Email: \\ Liming Zhang ${ }^{*}$ - zhang@chem.ucsb.edu \\ * Corresponding author \\ Keywords: \\ enone; gold catalysis; oxidation; propargyl carboxylate
}

Open Access

\author{
Beilstein J. Org. Chem. 2013, 9, 1925-1930. \\ doi:10.3762/bjoc. 9.227 \\ Received: 06 July 2013 \\ Accepted: 23 August 2013 \\ Published: 24 September 2013 \\ This article is part of the Thematic Series "Gold catalysis for organic \\ synthesis II". \\ Guest Editor: F. D. Toste
}

(C) $2013 \mathrm{Ji}$ et al; licensee Beilstein-Institut.

License and terms: see end of document.

\begin{abstract}
Gold-catalyzed intermolecular oxidation of carboxylates of primary or secondary propargylic alcohols are realized with excellent regioselectivity, which is ascribed to inductive polarization of the $\mathrm{C}-\mathrm{C}$ triple bond by the electron-withdrawing carboxy group. The gold carbene intermediates thus generated undergo selective 1,2-acyloxy migration over a 1,2-C-H insertion, and the selectivities could be dramatically improved by the use of a $P, S$-bidentate ligand, which is proposed to enable the formation of tris-coordinated and hence less electrophilic gold carbene species. $\alpha$-Carboxy $\alpha, \beta$-unsaturated ketones/aldehydes can be obtained with fair to excellent yields.
\end{abstract}

\section{Introduction}

We reported in 2010 [1] that $\alpha$-oxo gold carbenes could be conveniently generated as reactive intermediates in goldcatalyzed intermolecular oxidation of alkynes. By using pyridine $N$-oxides [1] and later 8 -substituted quinoline $N$-oxides [2] as the external oxidants, this approach permits a safe and efficient access to $\alpha$-oxo gold carbenes without resorting to the dediazotization strategy [3-5] using hazardous and potentially explosive diazo substrates (Scheme 1). Since then an array of versatile synthetic methods has been developed based on the general approach by us [2,6-12] and other researchers [13-20], thus making it an exciting area for further advancing gold chemistry.

Among various types of alkynes examined, internal alkynes, while without incident in the generation of the gold carbene intermediates, present an additional challenge, namely how to control the regioselectivity of the oxidation. We reported previously that synthetically useful regioselectivity could be 


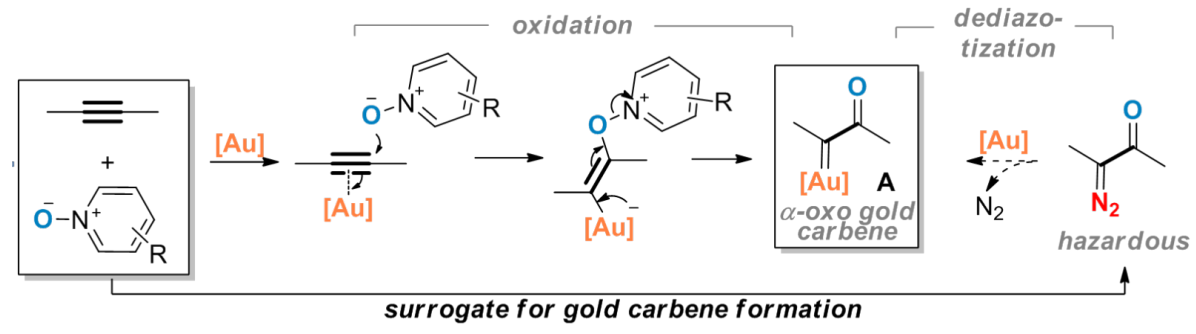

Scheme 1: Generation of a-oxo gold carbenes via intermolecular oxidation of alkynes: a non-diazo approach.

achieved if the two ends of the $\mathrm{C}-\mathrm{C}$ triple bond are biased by a steric bulk and/or via conjugation (Scheme 2). In our continued effort to reveal regioselectivities of this oxidation with different types of internal alkynes, we examined propargylic carboxylates, which have served as a versatile platform for the development of a diverse range of gold catalysis [21]. Herein we report our findings and the development of a reliable synthesis of $\alpha$-carboxy $\alpha, \beta$-unsaturated ketones/aldehydes.

\section{Results and Discussion}

We began by subjecting the propargylic acetate 4a to the suitable conditions developed in our previous study, namely $\operatorname{IPrAuNTf}_{2}(5 \mathrm{~mol} \%)$ and 8 -methylquinoline $\mathrm{N}$-oxide (3, 1.5 equiv) in 1,2-dichloroethane at ambient temperature. To our delight, the reaction proceeded efficiently, yielding the $\alpha$-acetoxyenone 5a-OAc $(Z / E>50: 1)$ and the isomeric $\beta$-acetoxyenone $\mathbf{5 a - H}$ in an excellent combined $92 \%$ yield along with a minute amount of the enone $6(<0.5 \%$, Scheme 3$)$; moreover, 5a-OAc is favored over $\mathbf{5 a - H}$ by a ratio of $\sim 7: 1$. Of particular importance is that the anticipated isomer $\mathbf{5 a}$ ', accessible via the gold carbene B' from a regioisomeric alkyne oxidation, was not positively detected due to the trace amount $(<0.5 \%)$, thereby revealing an exceptional level of regioselectivity in the oxidation of this type of internal alkynes. The formations of 5a-OAc and 5a-H are rationalized as the results of divergent transformations of the $\alpha$-oxo gold carbene $\mathbf{B}$ : the former is formed via a two-step 2,3-acetoxy migration [22,23], and the latter most likely via a concerted carbene $1,2-\mathrm{C}-\mathrm{H}$ insertion[2] The selective formation of the $Z$ isomer of 5a-OAc can be attributed to that $\mathbf{B}$ adopts a preferred conformation, as detailed in Scheme 3, in order to avoid steric interaction between $\mathrm{Me}$ and the acyl moiety. It needs to be noted that a related intramolecular version of this reaction has been previously reported [24].

An alternative mechanism for the formation of 5a-OAc is also shown in Scheme 3 (the top half). Instead of initially undergoing oxidative gold carbene formation, a gold-promoted 1,2acetoxy migration [25] would generate a vinyl gold carbene intermediate (i.e., $\mathbf{C}$ ), which can then be oxidized by $\mathbf{3}$ to yield the product. However, this scenario is deemed unlikely by the following observations and considerations: a) propargylic carboxylates of type 4a with an internal $\mathrm{C}-\mathrm{C}$ triple bond typically undergo facile 3,3-rearrangements [26-30] instead of 1,2acyloxy migrations. The former process would eventually lead to the formation of the enones 6 [31]. Due to hydrolysis, only under thermal and anhydrous conditions products derived from the latter processes can be predominantly formed [32]; under our conditions (at ambient temperature and without exclusion of moisture), the enone 6 was indeed detected but in a minute amount, suggesting that the 1,2-acyloxy migration might be an even less meaningful event in the reaction; $b$ ) it is known that the gold carbenes of type $\mathbf{B}$ can be readily oxidized by $\mathrm{Ph}_{2} \mathrm{~S}=\mathrm{O}$ [33], which, however, is an inefficient oxidant for generating $\alpha$-oxo gold carbenes of type A via alkyne oxidation [34,35]; when the $N$-oxide $\mathbf{3}$ is replaced by the sulfoxide, 5a-OAc was formed in only $5 \%$ yield even at $60{ }^{\circ} \mathrm{C}$ after $12 \mathrm{~h}$ (Scheme 4); moreover, the major product in the reaction was the expected<smiles>CCCC#CC1CCCCC1</smiles>

$1 \mathrm{a}$

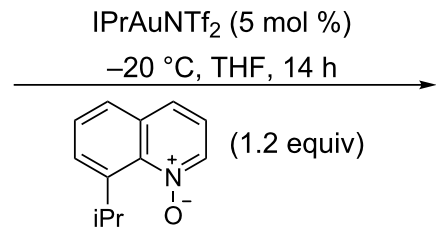

$90 \%$ yield

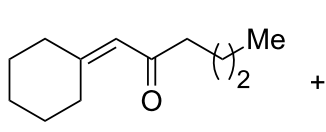

$2 a$

13<smiles>CCNC=CC(=O)C1CCCCC1</smiles>

2a'

Scheme 2: Gold-catalyzed regioselective oxidation of a sterically biased internal alkyne. 


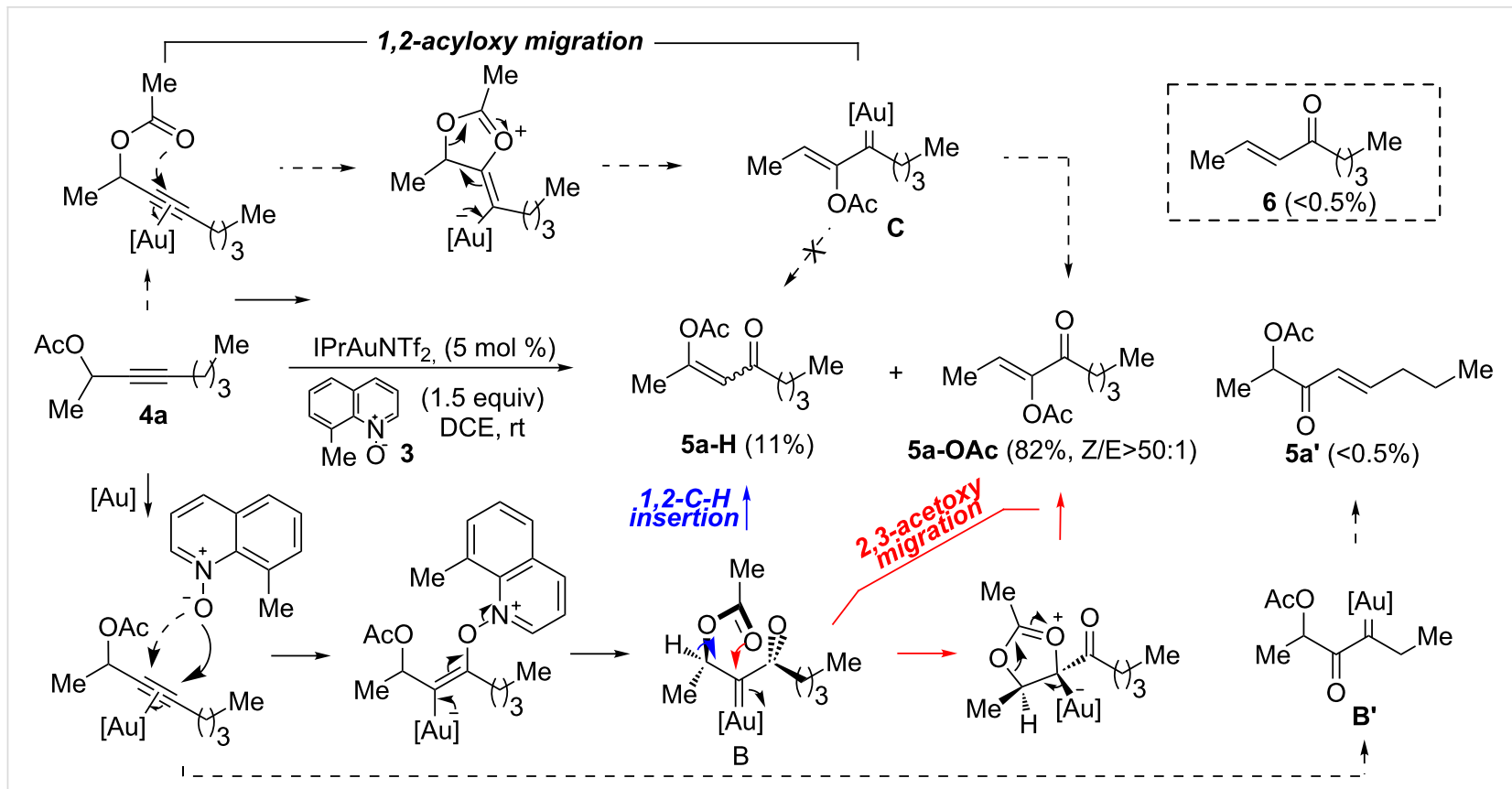

Scheme 3: Gold-catalyzed oxidation of the propargylic acetate $4 \mathbf{a}$ and the mechanistic rationale

enone 6 (56\% yield, $88 \%$ conversion) due to a dominant goldcatalyzed 3,3-rearrangement; c) this alternative could not rationalize the formation of $\mathbf{5 a - H}$.

The fact that in the presence of the oxidant 3 the previously observed facile transformations of propargylic carboxylates (i.e., 3,3-rearrangement and 1,2-acyloxy migration) are no longer competitive with the oxidative catalysis is surprising and suggests that this oxidation process could divert substrates from other well established, facile gold catalysis to the formation of distinctively different functional products in the presence of oxidants.

The relatively low selectivity (i.e., $~ 7: 1$ ) of 5a-OAc over $\mathbf{5 a - H}$ was drastically improved upon catalyst screening. It was eventually found that the ratio could reach $>200: 1$ by using the gold(I) catalyst derived from our previously developed bulky $P, S$-bidentate ligand L1 (Figure 1) [11]. A similarly high selectivity was also achieved by using the $P, N$-bidentate ligand MorDalPhos [36,37]. However, the $Z / E$ ratios of 5a-OAc in the former case is $\sim 13: 1$, better than $\sim 7: 1$ in the latter case, albeit both lower than that by $\operatorname{IPrAuNTf}_{2}(>50: 1$, see Scheme 3$)$. The enhanced preference of $\mathrm{AcO}$ migration en route to the formation of 5a-OAc over the 1,2-C-H insertion is attributed to attenuation of the electrophilicity of the gold carbene moiety via the formation of a tris-coordinated gold complex (i.e., D) [11].

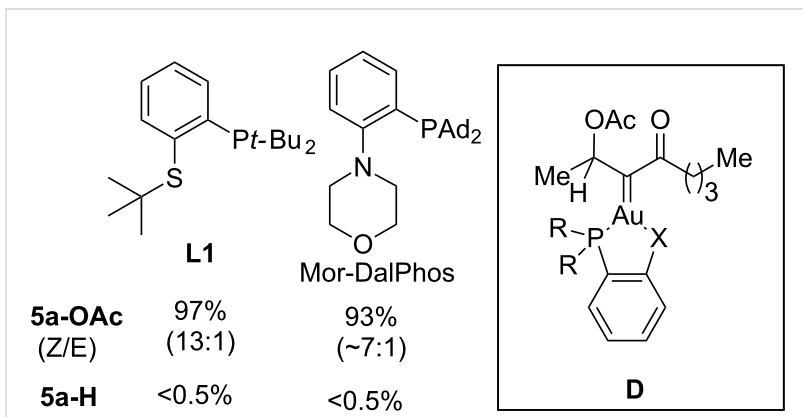

Figure 1: The impact of ligands on the ratio of $5 \mathrm{a}-\mathbf{O A c}$ and $\mathbf{5 a}-\mathbf{H}$ in the gold-catalyzed oxidation of $4 \mathrm{a}$ (reaction conditions: $5 \mathrm{~mol} \%$ gold catalyst, 1.5 equiv of $3, \mathrm{DCE}, \mathrm{rt}, 3 \mathrm{~h}$ ).
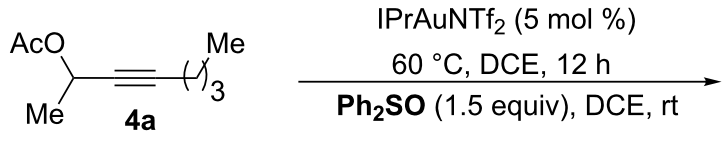

$88 \%$ conversion<smiles>[C+]OC(=CC)C(=O)O[Na]</smiles><smiles>CC=CC(C)=O</smiles>

5a-OAc $(5 \%)$ 
The scope of this alkyne oxidation/acetoxy migration reaction is outlined in Table 1. Acetates derived from primary/secondary propargylic alcohols with various substitution patterns and containing different functional groups were all allowed, although the tertiary counterpart underwent gold-catalyzed 3,3rearrangement preferentially [21] and hence was not a viable substrate. Except entry 7, the gold-catalyzed oxidations proceeded with excellent regioselectivities $(>25: 1)$, and the desired $\alpha$-acyloxy $\alpha, \beta$-unsaturated ketones/aldehyde were isolated with fair to excellent yields. While the bulky catalyst $\mathrm{Me}_{4} t$-BuXPhosAuNTf 2 [38] was used in entry 1 to obtain a better oxidation regioselectivity (28/1), it did not lead to a good ratio in the case of $\mathbf{4 h}$ (entry 7 ), where the oxidation regioisomer of type 5a' was formed in $23 \%$ yield. This outcome is rationalized in the next paragraph. In the case of pivalate $\mathbf{3 c}$ with a terminal alkyne (entry 2), the use of this bulky acyl group instead of acetyl is to curtail the hydrolytic formation of the corresponding $\alpha$-ketoaldehyde. In many cases the ratios of

Table 1: Reaction scope studies for the formation of $\alpha$-acetoxyenones from propargyl acetates. ${ }^{\text {a }}$

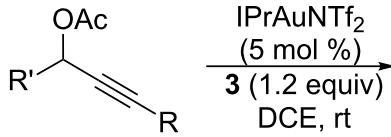

4<smiles></smiles>

5-H

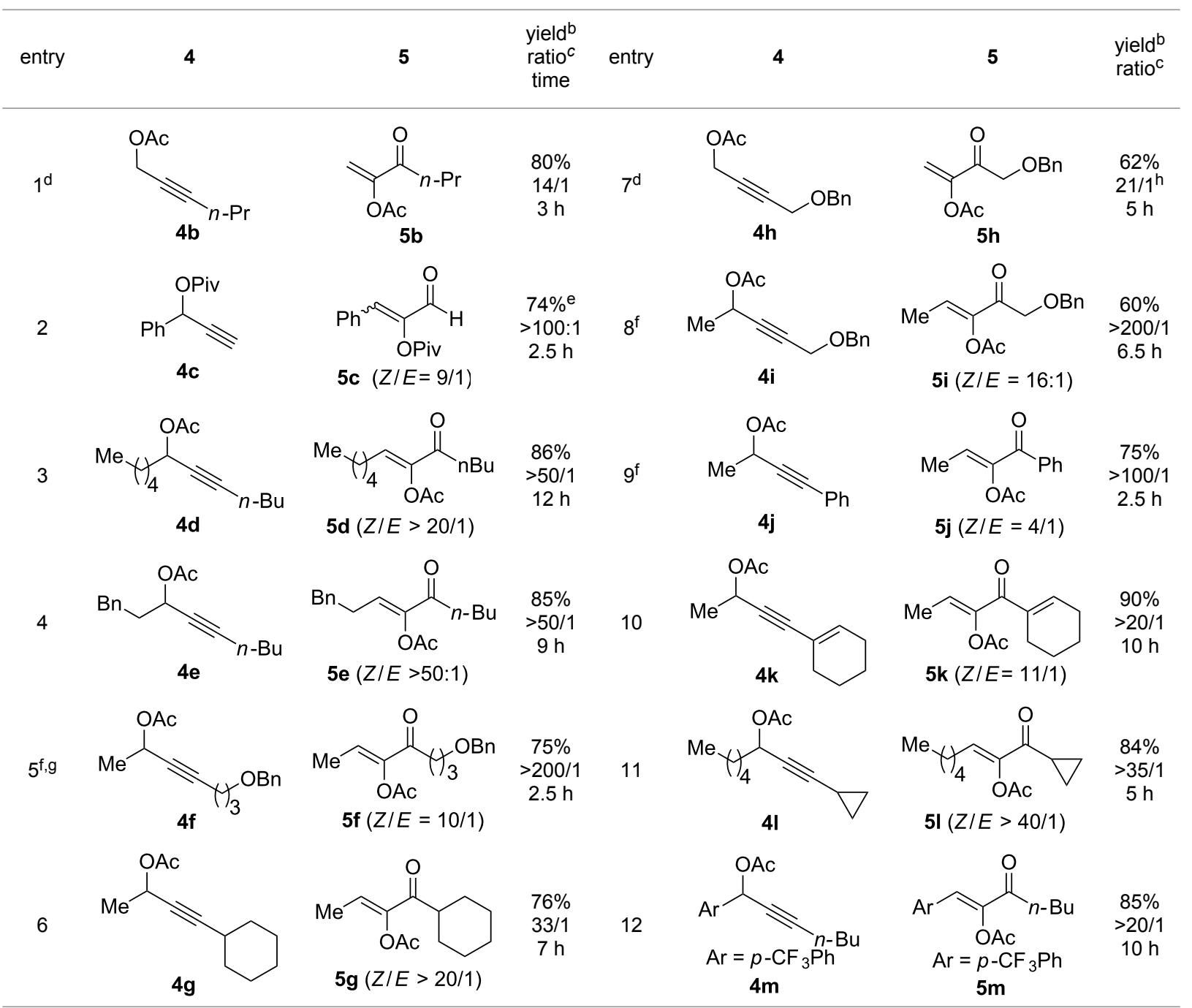

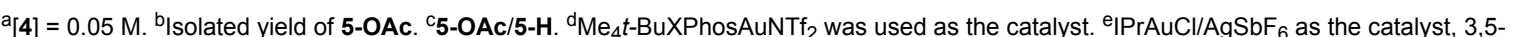
dicholoropyridine $\mathrm{N}$-oxide (2 equiv) as the oxidant, and DCM as the solvent. ${ }^{\mathrm{f}} \mathrm{L1} \mathrm{AuCl} / \mathrm{AgNTf}_{2}$ used as catalyst. ${ }^{\mathrm{g}} 10 \mathrm{~mol} \%$ catalyst. ${ }^{\mathrm{h}} \mathrm{The}$ oxidation regioisomer of type $\mathbf{5} a^{\prime}$ ' was formed in a $23 \%$ yield. 
5-OAc and 5-H were high with IPrAuNTf 2 as the catalyst; for the ones with low selectivities, $\mathbf{L 1 A u N T f}_{2}$ offered again dramatic improvements (entries 5,8 and 9) although at the expense of the geometric selectivities of the major product.

The excellent regioselectivities of gold-catalyzed oxidations of propargylic carboxylates, albeit unexpected, could be readily rationalized by invoking inductive polarization of the $\mathrm{C}-\mathrm{C}$ triple bond by the electronegative carboxy group. Such polarization could be revealed by calculated natural charges via natural population analysis [39] and corroborated by experimentally detectable properties such as $\mathrm{p} K_{\mathrm{a}}$ [40] and ${ }^{13} \mathrm{C}$ NMR [41]. We calculated the natural charges at the sp-hybridized carbons in $\mathbf{4 a}$ using the Density Functional Theory (B3LYP/6-31G*, Spartan06). The NC is 0.230 for the $\mathrm{C}(\mathrm{sp})$ distal to the carboxy group and -0.081 for the proximal $\mathrm{C}(\mathrm{sp})$, revealing a strong inductive effect that leads to a more electron-defficient distal alkyne end (Figure 2). This revelation is consistent with the ${ }^{13} \mathrm{C}$ NMR chemical shifts of the alkynyl carbons. The observed regioselectivity can be ascribed to a selective attack of the nucleophilic oxidant to the more electrophilic distal C(sp). Notably, a recently published Pt-catalyzed hydrosilylation on a similar substrate showed a 3.7:1 regioselectivity [42]. This unexpectedly high selectivity with gold catalysis is attributed to the augmentation of the electronic bias of the $\mathrm{C}-\mathrm{C}$ triple bond via the gold activation. The decreased regioselectivity with $\mathbf{4 h}$ (entry 7) is due to the counter polarization of the $\mathrm{C}-\mathrm{C}$ triple bond by the propargylic $\mathrm{BnO}$ group. The better result with $4 \mathbf{i}$ also containing a similarly positioned $\mathrm{BnO}$ group (entry 8 ) is attributed to the synergistic effect of the steric bias [2].

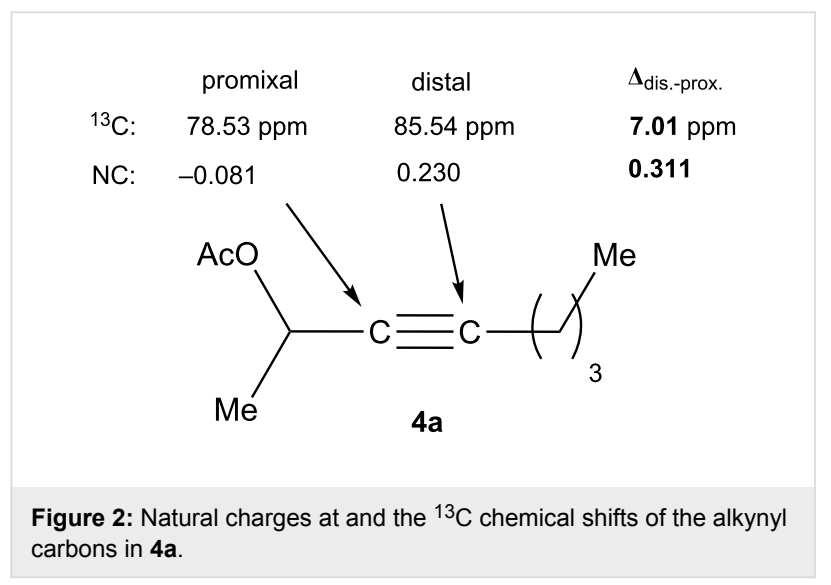

While a previous Pd catalysis [43] could also accomplish this transformation, the demonstrated scope is much limited, and the catalyst loading is $20 \%$. With this oxidative gold catalysis, the propargyl esters, except those derived from tertiary alcohols, can be reliably converted into $\alpha$-acyloxy $\alpha, \beta$-unsaturated ketones/aldehydes.

\section{Conclusion}

We have realized a gold-catalyzed, highly regioselective oxidation of carboxylates of primary and secondary propargylic alcohols by utilizing inductive polarization of the C-C triple bond by the electron-withdrawing carboxy moiety. The $\alpha$-oxo gold carbene intermediates generated can selectively undergo 1,2-acyloxy migrations over 1,2-C-H insertion. This inherent selectivity can be much enhanced by the use of our previously developed $P, S$-bidentate ligand, which enables the generation of tri-coordinated and less electrophilic gold carbene species. $\alpha$-Acyloxy $\alpha, \beta$-unsaturated ketones/aldehydes can be obtained with fair to excellent yields.

\section{Supporting Information}

\section{Supporting Information File 1}

Experimental procedure, compound characterization, and NMR spectra.

[http://www.beilstein-journals.org/bjoc/content/

supplementary/1860-5397-9-227-S1.pdf]

\section{Acknowledgements}

The authors are grateful for the financial support from NSF (CHE-1301343).

\section{References}

1. Ye, L.; Cui, L.; Zhang, G.; Zhang, L. J. Am. Chem. Soc. 2010, 132, 3258-3259. doi:10.1021/ja100041e

2. Lu, B.; Li, C.; Zhang, L. J. Am. Chem. Soc. 2010, 132, 14070-14072. doi:10.1021/ja1072614

3. Doyle, M. P.; McKevey, M. A.; Ye, T. Modern Catalytic Methods for Organic Synthesis with Diazo Compounds: From Cyclopropanes to Ylides; Wiley: New York, 1998.

4. Davies, H. M. L.; Beckwith, R. E. J. Chem. Rev. 2003, 103, 2861-2903. doi:10.1021/cr0200217

5. Taber, D. F. In Carbon-Carbon $\Sigma$-Bond Formation; Pattenden, G., Ed.; Pergamon Press: Oxford, UK, 1991; pp 1045-1062.

6. Ye, L.; He, W.; Zhang, L. J. Am. Chem. Soc. 2010, 132, 8550-8551. doi:10.1021/ja1033952

7. He, W.; Li, C.; Zhang, L. J. Am. Chem. Soc. 2011, 8482-8485. doi:10.1021/ja2029188

8. Ye, L.; He, W.; Zhang, L. Angew. Chem., Int. Ed. 2011, 50, 3236-3239. doi:10.1002/anie.201007624

9. Wang, Y.; Ji, K.; Lan, S.; Zhang, L. Angew. Chem., Int. Ed. 2012, 51, 1915-1918. doi:10.1002/anie.201107561

10. Ji, K.; Zhao, Y.; Zhang, L. Angew. Chem., Int. Ed. 2013, 52, 6508-6512. doi:10.1002/anie.201301601

11. Luo, Y.; Ji, K.; Li, Y.; Zhang, L. J. Am. Chem. Soc. 2012, 134, 17412-17415. doi:10.1021/ja307948m

12. He, W.; Xie, L.; Xu, Y.; Xiang, J.; Zhang, L. Org. Biomol. Chem. 2012, 10, 3168-3171. doi:10.1039/c2ob25235j

13. Bhunia, S.; Ghorpade, S.; Huple, D. B.; Liu, R.-S.

Angew. Chem., Int. Ed. 2012, 51, 2939-2942.

doi:10.1002/anie.201108027 
14. Vasu, D.; Hung, H.-H.; Bhunia, S.; Gawade, S. A.; Das, A.; Liu, R.-S. Angew. Chem., Int. Ed. 2011, 50, 6911-6914.

doi:10.1002/anie.201102581

15. Henrion, G.; Chava, T. E. J.; Le Goff, X.; Gagosz, F. Angew. Chem., Int. Ed. 2013, 52, 6277-6882. doi:10.1002/anie.201301015

16. Hashmi, A. S. K.; Wang, T.; Shi, S.; Rudolph, M. J. Org. Chem. 2012, 7761-7767. doi:10.1021/jo301381z

17. Xu, M.; Ren, T.-T.; Li, C.-Y. Org. Lett. 2012, 14, 4902-4905. doi:10.1021/ol302238t

18. Dateer, R. B.; Pati, K.; Liu, R.-S. Chem. Commun. 2012, 48 , 7200-7202. doi:10.1039/c2cc33030j

19. Qian, D.; Zhang, J. Chem. Commun. 2011, 47, 11152-11154. doi:10.1039/c1cc14788a

20. Davies, P. W.; Cremonesi, A.; Martin, N. Chem. Commun. 2011, 47, 379-381. doi:10.1039/c0cc02736g

21. Wang, S.; Zhang, G.; Zhang, L. Synlett 2010, 692-706. doi:10.1055/s-0029-1219527

22. Mamane, V.; Gress, T.; Krause, H.; Fuerstner, A. J. Am. Chem. Soc. 2004, 126, 8654-8655. doi:10.1021/ja048094q

23. Harrak, Y.; Blaszykowski, C.; Bernard, M.; Cariou, K.; Mainetti, E.; Mouriès, V.; Dhimane, A.-L.; Fensterbank, L.; Malacria, M. J. Am. Chem. Soc. 2004, 126, 8656-8657. doi:10.1021/ja0474695

24. Murai, M.; Kitabata, S.; Okamoto, K.; Ohe, K. Chem. Commun. 2012, 48, 7622-7624. doi:10.1039/c2cc32628k

25. Johansson, M. J.; Gorin, D. J.; Staben, S. T.; Toste, F. D. J. Am. Chem. Soc. 2005, 127, 18002-18003. doi:10.1021/ja0552500

26. Zhang, L. J. Am. Chem. Soc. 2005, 127, 16804-16805. doi:10.1021/ja056419c

27. Wang, S.; Zhang, L. J. Am. Chem. Soc. 2006, 128, 8414-8415. doi:10.1021/ja062777j

28. Wang, S.; Zhang, L. M. Org. Lett. 2006, 8, 4585-4587. doi:10.1021/ol0618151

29. Zhang, L.; Wang, S. J. Am. Chem. Soc. 2006, 128, 1442-1443. doi:10.1021/ja057327q

30. Marion, N.; Díez-González, S.; de Fremont, P.; Noble, A. R.; Nolan, S. P. Angew. Chem., Int. Ed. 2006, 45, 3647-3650. doi:10.1002/anie.200600571

31. Yu, M.; Li, G.; Wang, S.; Zhang, L. Adv. Synth. Catal. 2007, 349, 871-875. doi:10.1002/adsc.200600579

32. Li, G.; Zhang, G.; Zhang, L. J. Am. Chem. Soc. 2008, 130, 3740-3741. doi:10.1021/ja800001h

33. Witham, C. A.; Mauleon, P.; Shapiro, N. D.; Sherry, B. D.; Toste, F. D. J. Am. Chem. Soc. 2007, 129, 5838-5839. doi:10.1021/ja071231+

34. Cuenca, A. B.; Montserrai, S.; Hossain, K. M.; Mancha, G.; Lledós, A.; Medio-Simón, M.; Ujaque, G.; Asensio, G. Org. Lett. 2009, 11, 4906-4909. doi:10.1021/ol9020578

35. Li, C.-W.; Pati, K.; Lin, G.-Y.; Sohel, S. M. A.; Hung, H.-H.; Liu, R.-S. Angew. Chem., Int. Ed. 2010, 49, 9891-9894. doi:10.1002/anie.201004647

36. Lundgren, R. J.; Peters, B. D.; Alsabeh, P. G.; Stradiotto, M. Angew. Chem., Int. Ed. 2010, 49, 4071-4074. doi:10.1002/anie.201000526

37. Hesp, K. D.; Stradiotto, M. J. Am. Chem. Soc. 2010, 132, 18026-18029. doi:10.1021/ja109192w

38. Wang, Y.; Ji, K.; Lan, S.; Zhang, L. Angew. Chem., Int. Ed. 2012, 51, 1915-1918. doi:10.1002/anie.201107561

39. Reed, A. E.; Weinstock, R. B.; Weinhold, F. J. Chem. Phys. 1985, 83, 735-746. doi:10.1063/1.449486
40. Gross, K. C.; Seybold, P. G.; Hadad, C. M. Int. J. Quant. Chem. 2002, 90, 445-458. doi:10.1002/qua.10108

41. Levy, J. B. Struct. Chem. 1999, 10, 121-127. doi:10.1023/A:1022033330273

42. Rooke, D. A.; Ferreira, E. M. Angew. Chem., Int. Ed. 2012, 51, 3225-3230. doi:10.1002/anie.201108714

43. Bartels, A.; Mahrwald, R.; Müller, K. Adv. Synth. Catal. 2004, 346, 483-485. doi:10.1002/adsc.200303200

\section{License and Terms}

This is an Open Access article under the terms of the Creative Commons Attribution License

(http://creativecommons.org/licenses/by/2.0), which permits unrestricted use, distribution, and reproduction in any medium, provided the original work is properly cited.

The license is subject to the Beilstein Journal of Organic Chemistry terms and conditions:

(http://www.beilstein-journals.org/bjoc)

The definitive version of this article is the electronic one which can be found at: doi:10.3762/bjoc. 9.227 